\title{
Status of Sabaki Tilapia Aquaculture in the Kingdom of Saudi Arabia
}

\author{
Benjamin C Young ${ }^{1,2 *}$, Ali A Shabi ${ }^{1}$, Talal T Hajuji ${ }^{1}$, Riyadh Hussain Alfaggeh ${ }^{1}$ and Ibrahim AlMoutiri ${ }^{1}$ \\ ${ }^{1}$ National Fisheries Center, Ministry of Environment, Water \& Agriculture, Jeddah 21423, Kingdom of Saudi Arabia \\ ${ }^{2}$ Taiwan International Cooperation and Development Fund, Taipei 11047, Taiwan
}

*Corresponding author: Benjamin C Young, Prince Abdullah AlFiasal St, Al

Zummrad, Jeddah 23823, Kingdom of Saudi Arabia.

Received Date: November 14, 2020

Published Date: November 30, 2020

\section{Opinion}

Since 1980s, shrimp farming has been increasingly prosperous in the Kingdom of Saudi Arabia (henceforth, Saudi Arabia) owing to economic development, market demand, and environmental factors. Initially, the primary species being cultured was the Indian prawn (Fenneropenaeus indicus). However, the white spot syndrome virus, which emerged in 2010, decimated this species and since then aquaculture industries in Saudi Arabia have started farming specific pathogen-free white shrimp (Litopenaeus vannamei) to cover the shortage of producing Indian prawns. Currently, shrimp farming is widespread in Saudi Arabia to meet global demand. Presently, the total aquaculture production of Saudi Arabia is $\sim 83,000$ tons, and shrimp farming accounts for $\sim 70 \%$ of the total aquaculture production. The primary farmed fish species Sabaki tilapia (Oreochromis spilurus), Nile tilapia (Oreochromis niloticus), Asian sea bass (Lates calcarifer), and gilt-head bream (Sparus aurata) contributed 15,000 tons to the total production in 2019. Note that because of overproduction, the price of Asian sea bass has been decreasing. Moreover, the fingerling source of gilt-head bream depends on imports; therefore, tilapia's culture is gaining popularity. Among the various tilapia species, the Sabaki tilapia is one of the unique and higher economic value species in the global tilapia aquaculture industry. Due to market demand and environmental factors, fisheries authority selected Sabaki tilapia to target the aquaculture development projects' species, while the commercial culture of Sabaki tilapia had not been developing in Saudi Arabia. The project has been beginning since 2018. However, in the farming period, the Sabaki tilapia culture had confronted several difficulties, such as extreme salinity. On the coastline of Jeddah, West Saudi Arabia, seawater's salinity is 42 to $45 \%$ during the producing period in 35 to $42^{\circ} \mathrm{C}$ water temperature. Furthermore, the regulations strictly prohibit the installation of pumping wells, and freshwater only purchased through water companies, so salinity adjustment is also one of the critical costs. In addition, there is a lack of information on the commercial scale of Sabaki tilapia in Saudi Arabia. Despite Sabaki tilapia becoming more prevalent in aquaculture production in Saudi Arabia, there is a lack of information on the farming operations. Therefore, we conducted trial systems that focused on the types of Sabaki tilapia aquaculture practices in Saudi Arabia. We attempted several farming systems to understand the best result for the spawning and grow-out stage. The four farming systems are earth pond, net cage, raceway, and arena, respectively. The practice results, the raceway, and arena have superior fry production results than the net cage and earth pond. Also, the net cage required further management skills and costs. Furthermore, the reproductive performance of a female brood stock can spawn 120 to 550 fries. The hatching rate is more than $95 \%$. The fry of Sabaki tilapia has strong cannibalism. Therefore, the grading is necessary. The nutritional requirements of Sabaki tilapia were crude protein 35 to $45 \%$ and crude fat 10 to $15 \%$. The feed conversion ratio (FCR) of the grow-out stage was 1.2 to 1.4 ; the raceway and net cage have superior growth performance than the earth pond. Generally, the farming measure of Sabaki tilapia has not vast differences comparing other tilapia species. However, because of the unique farming environment in Saudi Arabia, the 
farming environment was under high salinity and temperature in the producing period. Notably, the bacterial infection continually emerges in the winter season. Moreover, our survey reported that the primary costs of Sabaki tilapia aquaculture production were feed (50.06\%-69.33\%), labor (14.51\%-20.98\%), and fry (5.29\%-5.81\%). Most aquaculture companies in Saudi Arabia are either industrial or large-scale businesses. In developing countries, this is important because the scale of farming operations makes a significant difference. Significantly, the industrial-scale producers spent less on feed as they could produce feed in their facilities. Because the major operating costs in Sabaki tilapia production were feed, labor, and fry, future aquaculture operations could emphasize cost control for producers and specific marketing and disease prevention strategies to enable the Sabaki tilapia industry's sustainability in Saudi Arabia.

\section{Acknowledgment}

None.

\section{Conflicts of Interest}

The authors declare that they have no conflict of interest. 